2018-03

\title{
A multi-technique experimental and modelling study of the porous structure of IG-110 and IG-430 nuclear graphite
}

Jones, Katie Louise

http://hdl.handle.net/10026.1/10403

10.1016/j.carbon.2017.11.076

Carbon

Elsevier

All content in PEARL is protected by copyright law. Author manuscripts are made available in accordance with publisher policies. Please cite only the published version using the details provided on the item record or document. In the absence of an open licence (e.g. Creative Commons), permissions for further reuse of content should be sought from the publisher or author. 
This is the author's accepted manuscript. The final published version of this work (the version of record) is published by Elsevier in Carbon (March 2018) available at: http://doi.org/10.1016/j.carbon.2017.11.076. This work is made available online in accordance with the publisher's policies. Please refer to any applicable terms of use of the publisher.

\title{
A multi-technique experimental and modelling study of the porous structure of IG-110 and IG-430 nuclear graphite.
}

\author{
Katie L. Jones ${ }^{\mathrm{a}}$, Giuliano M. Laudone ${ }^{\mathrm{a}, *}$, G. Peter Matthews ${ }^{\mathrm{a}}$ \\ ${ }^{a}$ Faculty of Science and Engineering, Plymouth University, Plymouth, UK.
}

\begin{abstract}
In nuclear graphite, the wide range of void sizes precludes a full characterisation of pore volume by means of a single technique. A novel multi-technique approach, consisting of pycnometry, low pressure gas adsorption and mercury porosimetry is presented. The approach is validated for two nuclear-grade graphites designed for use in Generation IV nuclear reactors, namely IG-110 and IG-430. Damage and deformation caused to the structure of the graphite by mercury intrusion is estimated by consecutive intrusion experiments. The damage is assumed to be caused by the highest applied pressures of mercury. It is compensated by substituting that part of the percolation curve with one derived from adsorption measurements. The various measurements are inverse modelled in a way which intelligently bridges the size gap between the techniques. The resulting complete non-hierarchical pore structure covers size spanning 4 orders of magnitude. The new approach resolves the long standing issues associated with performing porosimetry on graphitic samples, and fills the gap in knowledge for the assessment of multilevel porosity within graphite. As an example of the possible applications of the resulting void network structure, we calculated the air network flow capacity, related to absolute permeability, for the two graphite samples.
\end{abstract}

\footnotetext{
* Corresponding author.

Email address: glaudone@plymouth.ac.uk (Giuliano M. Laudone)
} 
This is the author's accepted manuscript. The final published version of this work (the version of record) is published by Elsevier in Carbon (March 2018) available at: http://doi.org/10.1016/j.carbon.2017.11.076. This work is made available online in accordance with the publisher's policies. Please refer to any applicable terms of use of the publisher.

\section{Introduction}

Graphite has long been incorporated into a variety of nuclear reactor designs, from the very first CP-1 experimental reactor built in 1942, through Magnox and RBMK reactors [1], to the advanced gas-cooled reactors (AGR) currently operational in the UK. Because of its mechanical and thermal properties, combined with its behaviour as a neutron moderator and reflector, nuclear-grade graphite is also used as a moderator and structural core material in GenerationIV reactor designs, such as the high-temperature gas-cooled reactors (HTGR) and molten salt reactors $[2,3]$.

Nuclear graphites comprise coke filler particles and a binder phase. A typical production process is to calcine the pitch or petroleum coke filler particles at temperatures above $1000{ }^{\circ} \mathrm{C}$ in order the remove volatile species. The coke filler particles are then ground and mixed with a pitch binder. This mixture is first baked at 800 to $1000{ }^{\circ} \mathrm{C}$, re-impregnated with pitch in order to increase its bulk density, and finally graphitised in an inert atmosphere at temperatures above $2500{ }^{\circ} \mathrm{C}$. As a result of this manufacturing process, nuclear-grade graphite is a complex polycrystalline solid. However, it also encompasses a pore network with void sizes spanning the micro- $(<2 \mathrm{~nm})$ to macroporous $(>50 \mathrm{~nm})$ size range developed during the baking stage because of the evolution of gas, and fine shrinkage Mrozowski cracks. Different graphite grades show large variation in the relative composition of filler and binder phases, as well as void size and shapes of microcracks [4].

Under fast neutron irradiation, the properties of graphite change: individual crystals undergo dimensional changes, while the bulk properties of the material, such as Young's modulus and coefficient of thermal expansion, are also affected [5]. These irradiation-induced microstructural changes and their effects on the bulk properties of nuclear graphite have been extensively studied [6-9] and modelled [10-13] as changes to the graphite's microstructure due to neutron irradiation damage could adversely affect the operational life of a reactor $[14,15]$.

The properties of nuclear graphite as a structural and moderating material can also be affected by oxidative processes. In Magnox reactors and AGRs, which employ $\mathrm{CO}_{2}$ as coolant, radiolytic oxidation can cause significant mass loss of the core graphite [16], which could reduce its effectiveness as neutron 
This is the author's accepted manuscript. The final published version of this work (the version of record) is published by Elsevier in Carbon (March 2018) available at: http://doi.org/10.1016/j.carbon.2017.11.076. This work is made available online in accordance with the publisher's policies. Please refer to any applicable terms of use of the publisher.

moderator and affect its mechanical strength [17-19]. While radiolytic oxidation, due to different coolants compositions, is not present in Generation-IV reactors, thermal oxidation of the graphite could occur. Graphite itself is not readily combustible due to the lack of volatile species [20], but, when exposed to oxygenated environments at elevated temperatures $\left(>450{ }^{\circ} \mathrm{C}\right)$, the solid phase of the material will undergo thermal oxidation [21]. In HTGRs, oxidizing impurities could be introduced into the system with the coolant (helium) gas under normal operating conditions. Air ingress into the core of a reactor, following an accidental loss of coolant gas, could also cause severe oxidation of the core graphite [22]. Porosity and pore sizes in nuclear graphite change as oxidation degrades the structural and mechanical properties of the graphite [23-26]. The size and geometry of pores are known to affect oxidation behaviour $[16,27]$, whilst studies suggest that factors such as grain size, internal surface area and density also impact oxidation rates [28]. In molten salt reactors, the size distribution of pores also determines the infiltration of the molten salt into the void structure of the graphite moderator [29]. Therefore, pore-level characterisation is critical for predicting the reactor safety and for assessing the viability of different grades of graphite material [21, 28, 30].

Previous research utilised a range of techniques, such as 3D X-ray tomography with image analysis $[28,31-34]$ or a combination of image analysis with other experimental techniques $[22,35-40]$ to investigate the effect of oxidation on the microstructure and bulk properties of nuclear graphites. However, techniques based on the image analysis of X-ray tomography suffer from shortcomings, both experimentally and in the interpretation of the results. The resolution of X-ray tomography images is related to the size of the samples under investigation and, in most cases, this limits the size of the void features that can be clearly identified to those larger than $2-4 \mu \mathrm{m}$. The interpretation of the tomography images also introduces a certain degree of subjectivity in the results, as the identification of void and solid features often relies on an arbitrarily defined thresholding of the image.

In this study, we attempt to provide accurate, quantitative information on the entire ranges of pore sizes present in the highly complex void network structure of nuclear graphite, through a multi-technique approach that com- 
This is the author's accepted manuscript. The final published version of this work (the version of record) is published by Elsevier in Carbon (March 2018) available at: http://doi.org/10.1016/j.carbon.2017.11.076. This work is made available online in accordance with the publisher's policies. Please refer to any applicable terms of use of the publisher.

bines experimental techniques probing different ranges of sizes, with a powerful modelling tool. While multi-technique approaches have been investigated in work by other authors [41-44], the approach used in this work is novel in both its application to graphitic samples, and its use of an explicit, deterministic void network model to straddle the entire void size range. In order to validate the applicability of this approach to the study of nuclear graphite, we investigated the porosity and pore size distribution of two virgin, fine-grain nuclear graphites, IG-110 and IG-430.

IG-110 and IG-430 are manufactured by Toyo Tanso Ltd, Japan, and are candidates for use in the cores of Generation-IV reactors. In order to develop a quantitative understanding of the complete porous space of both graphites, a multi-technique approach was essential, as one experimental technique alone can not cover the complete pore size range. For this study, gas adsorption analysis was used to investigate the surface area, using a traditional BET interpretation. Gas adsorption data was also interpreted using the commercial software BEL Master to obtain pore size distributions (PSD) in the microporous $(<2$ $\mathrm{nm}$ ) and mesoporous (2-50 nm) range [45] using grand canonical Monte Carlo (GCMC) simulations [46]. PSDs were also obtained using mercury porosimetry which span the mesoporous to macroporous ( $>50 \mathrm{~nm}$ ) range. Previously, studies have shown that traditional mercury porosimetry data obtained at the highest pressures, relating to intrusion of the smallest pore-throats, must be treated with caution due to damage and deformation of the graphite's microstructure $[47,48]$. To overcome this, the PSDs obtained from gas adsorption, which cover the smallest pore range, were compared and combined in a novel approach with those obtained from mercury porosimetry, to provide a combined void volume distribution that spans the entirety of the porous space.

Traditionally, a PSD would be obtained by taking the first derivative of the mercury intrusion curve and equating this to the void size distribution. However, this approach grossly underestimates the void space [49]. In this work, the cumulative void volume distributions are interpreted using the PoreXpert ${ }^{\circledR}$ modelling software which is able to give a more realistic interpretation of the porous network connectivity and void sizes [50]. Other measured values included bulk and He accessible densities, open pore volume (OPV) and closed pore 
This is the author's accepted manuscript. The final published version of this work (the version of record) is published by Elsevier in Carbon (March 2018) available at: http://doi.org/10.1016/j.carbon.2017.11.076. This work is made available online in accordance with the publisher's policies. Please refer to any applicable terms of use of the publisher.

volume $(\mathrm{CPV})$.

\section{Experimental procedure}

\subsection{Materials}

IG-110 and IG-430, also referred to as IG-11 and IG-43, were supplied by Toyo Tanso Ltd., Japan. IG-110 is a fine-grained, isotropic graphite which exhibits high thermal durability and strength, making it highly suitable for use in the nuclear industry. It is currently utilised in two of the existing HTGR cores, namely the Japanese High Temperature engineering Test Reactor (HTTR) [51] and the Chinese High Temperature Reactor-Pebble bed Modules (HTR-10) [52]. IG-430 is a comparable graphite, developed to display higher density, strength and thermal conductivity when compared with IG-110. Improved physical characteristics make it a suitable candidate for use in Generation-IV reactors. Table 1 shows some of the properties of the materials as listed by the manufacturers.

Table 1: Manufacturer's characterisation of the graphite types

\begin{tabular}{ccccccc} 
Grade & $\begin{array}{c}\text { Coke } \\
\text { derived } \\
\text { from }\end{array}$ & $\begin{array}{c}\text { Bulk } \\
\text { density } \\
/ \mathrm{g} \mathrm{cm}^{-3}\end{array}$ & $\begin{array}{c}\text { Coke filler } \\
\text { particle } \\
\text { size } / \mu \mathrm{m}\end{array}$ & $\begin{array}{c}\text { Tensile } \\
\text { strength } \\
/ \mathrm{MPa}\end{array}$ & $\begin{array}{c}\text { Young's } \\
\text { modulus } \\
/ \mathrm{GPa}\end{array}$ & $\begin{array}{c}\text { Thermal } \\
\text { conductivity } \\
/ \mathrm{W} \mathrm{m}^{-1} \mathrm{~K}^{-1}\end{array}$ \\
\hline IG-110 & Petrol & 1.77 & 10 & 25 & 9.8 & 120 \\
IG-430 & Pitch & 1.82 & 10 & 37 & 10.8 & 140 \\
\hline
\end{tabular}

\subsection{Sample preparation}

Square rods were sub-sampled from larger bricks of virgin graphite using a diamond blade. Each rod was then cut into cuboids of side lengths $\sim 5 \mathrm{~mm}$. All samples were sonicated in isopropanol for 24 hours to remove residual dust produced during cutting. Samples were then dried under vacuum for a minimum of $3 \mathrm{~h}$ at $305 \pm 5{ }^{\circ} \mathrm{C}$ using the BEL PREP-vac (MicrotracBEL, Japan) in order to remove any residual moisture from the samples surface. Drying was repeated between each experimental measurement.

\subsection{Pycnometry}

Helium and envelope pycnometry measurements were conducted under local ISO 9001:2008 protocols. Helium pycnometry was performed using the Pycnomatic ATC pycnometer (Thermo Fisher Scientific, Italy) which operated at 
This is the author's accepted manuscript. The final published version of this work (the version of record) is published by Elsevier in Carbon (March 2018) available at: http://doi.org/10.1016/j.carbon.2017.11.076. This work is made available online in accordance with the publisher's policies. Please refer to any applicable terms of use of the publisher.

a temperature of $20 \pm 0.01{ }^{\circ} \mathrm{C}$. Samples were loaded into a sample chamber of approximately $7 \mathrm{~cm}^{3}$ with a reference volume of approximately $20 \mathrm{~cm}^{3}$. Apparent density measurements were performed in triplicate and an average calculated.

Envelope pycnometry was performed on the same samples using a GeoPyc 1360 pycnometer (Micromeritics Corporation, USA) which measures the envelope volume of a sample by surrounding it with a flowing powder (DryFlo). The mass of the sample was then used to provide a value of bulk density. Samples were washed after analysis, following the procedure stated above, to remove residual DryFlo.

\subsection{Gas adsorption}

Low pressure gas adsorption was performed using a BELSORP-max volumetric gas adsorption instrument (MicrotracBEL, Japan). It incorporates a unique dead volume evaluation method, adsorption free space measurement (AFSM), which allows measurements to be taken free from environmental change. The system takes continuous readings to measure the change of free space at each data point, thus avoiding the need to maintain a constant coolant level. The system comprises of 3 pressure transducers of $0.0133 \mathrm{kPa}, 1.33 \mathrm{kPa}$ and $133 \mathrm{kPa}$ in full scale. This allows for high resolution measurements to be obtained over the extremely low relative pressure regions.

High precision gas adsorption/desorption isotherms for $\mathrm{N}_{2}$ were collected at $77 \mathrm{~K}$, i.e. with the sample surrounded by liquid nitrogen. The adsorption data was automatically recorded by the BELSORP-max analysis software in the relative pressure range: $10^{-8}<P / P_{0} \leqslant 0.997$, where $P$ is the pressure of the adsorbing gas, and $P_{0}$ is the saturated vapour pressure of $\mathrm{N}_{2}$, in this case atmospheric pressure. Adsorption data was manipulated using the BEL Master analysis software. Specific surface areas $\left(S_{\mathrm{BET}}\right)$ were determined using the standard Brunauer-Emmett-Teller (BET) function [53], which allows for multilayer adsorption. The relative pressure range $0.05-0.3$ was utilized to deduce the surface area, as at higher values of $P / P_{0}$ condensation occurred resulting in the non-linear relationship for the $P / V\left(P_{0}-P\right)$ versus $P / P_{0}$ plot, where $V$ is the volume of gas adsorbed. 
This is the author's accepted manuscript. The final published version of this work (the version of record) is published by Elsevier in Carbon (March 2018) available at: http://doi.org/10.1016/j.carbon.2017.11.076. This work is made available online in accordance with the publisher's policies. Please refer to any applicable terms of use of the publisher.

Grand-canonical Monte Carlo (GCMC) simulations, with different pore geometries, were generated from the $\mathrm{N}_{2}$ isotherms to provide PSDs that covered the micropore/mesopore range for the two IG graphites. Additionally, comparative surface areas $\left(S_{\mathrm{BJH}}\right)$ and PSDs related to mesopores and macropores were calculated by employing the Barrett-Joyner-Halenda (BJH) method [54], which allows for Kelvin condensation.

\subsection{Mercury porosimetry}

Lastly, the same samples were subjected to mercury porosimetry, performed using PASCAL 140 and PASCAL 440 mercury porosimeters (Thermo Fisher Scientific, Italy). All mercury porosimetry analyses were performed using local ISO 9001:2008 standard operating procedures. Intrusion was measured from vacuum to $400 \mathrm{MPa}$ applied pressure, and extrusion from $400 \mathrm{MPa}$ applied pressure to just above atmospheric pressure. The instruments were operated in a mode which allowed the mercury pressure to re-equilibrate when intrusion or extrusion was detected [50]. After analysis, samples were removed from the apparatus, and excess mercury disposed of before being re-weighed. The same samples were then placed in a vacuum pistol and heated to $360^{\circ} \mathrm{C}$ for 3 days under a vacuum of better than $0.13 \mathrm{~Pa}$, in an effort to remove the residual mercury from the internal pore network. An image of the set-up used for the thermal treatment of the samples can be found in the Supplementary information (SI) Figure 1. After the thermal treatment, samples were re-weighed, before a second mercury porosimetry run was performed on the samples. This second intrusion was carried out in order to assess the extent to which the experimental procedure caused damage to the microstructure during the first analysis. Examination of the consecutive runs determined the highest pressure point at which the damage onset had occurred in the first run and, consequently, the value at which the first percolation curve would be truncated, as explained in section 4.3.

The results were processed using the manufacturer's 'SOLID' software which automatically corrects the data for sample chamber and other extraneous factors by subtracting a blank run for the corresponding sample container ('dilatometer'). Traditionally, it is assumed that void features exposed to the non-wetting fluid (mercury displacing air or nominal vacuum, or air displacing water) are cylindrical, with diameter $d$. Then the features intruded at an applied pressure 

publisher's policies. Please refer to any applicable terms of use of the publisher.

$P$ are calculated by the Laplace equation:

$$
d \geqslant \frac{-4 \gamma \cos \theta}{P}
$$

In this work we use the commonly accepted value of $140^{\circ}$ for the contact angle $\theta$ of mercury intruding sandstone against residual air, and $0.48 \mathrm{Nm}^{-1}$ for the surface tension $\gamma$, while recognising the approximations in this choice of values [55].

\section{Modelling}

The software package PoreXpert ${ }^{\circledR}$ [56-58] was used to inverse model experimentally measured percolation characteristics and total accessible porosity, obtained as detailed in section 4.4, to generate simulated void network structures. The resulting networks are made up of identical unit cells with periodic boundary conditions. Each unit cell comprises cubic 'pores', centred on the nodes of a 3-dimensional lattice, and smaller cylindrical 'throats', which connect the pores in the three Cartesian directions. The spacial distribution of the void features within the simulated unit cell is determined by five modelling parameters, referred to as throat-skew, throat-spread, correlation level, pore-skew and connectivity. Throat-skew and throat-spread define the size distribution of the throats, the smaller features that control the percolation properties of the porous media. These are distributed between the values $d_{\min }$ and $d_{\max }$ (Equation 1) according to an Euler function that can describe Gaussian- and Poisson-like distributions [57]. The model can account for small-range correlation of the void features, which can lead to vertical or horizontal banding of the pores and throats according to their size; the level of such banding is defined by the correlation level parameter $\mathscr{C}$, which can vary between 0 , for a random structure, to 1 for a highly banded structure [59]. Connectivity defines the average number of throats connected to each pore of the void structure and can vary between 0 and 6 . The regular cubic packing of the void features in the simulated unit cells is inefficient and, in order to achieve the correct value of porosity, the size of the cubic pores needs to be increased by a factor defined by the pore-skew parameter; this may result in a pore size distribution strongly skewed towards the maximum pore size. These large void features could represent individual 
This is the author's accepted manuscript. The final published version of this work (the version of record) is published by Elsevier in Carbon (March 2018) available at: http://doi.org/10.1016/j.carbon.2017.11.076. This work is made available online in accordance with the publisher's policies. Please refer to any applicable terms of use of the publisher.

pores, but could also be clusters of pores and throats which mercury porosimetry, or other percolation measurements, cannot distinguish, as each cluster may be shielded by a single narrow throat, smaller than all the cluster's features.

The parameters of the modelled structures are optimised by a Boltzmannannealed amoeboid simplex, which compares the percolation properties and accessible porosity of thousands of simulated networks with the experimental inputs, and attempts to find the optimal combination of modelling parameters which minimizes the distance between the experimental and the modelled percolation characteristics.

The simulation software can perform calculations on the chosen representative structure in order to evaluate properties such as tortuosity, the network flow capacity of gases and liquids, imbibition by a wetting fluid, thermal conductivity and diffusion [56,60,61]. This void network modelling approach has been used in the characterisation of the properties of Gilsocarbon nuclear graphite [50] as well as a wide range of other porous materials, such a soil, oil and gas reservoir rocks, building materials, paper coating, membranes, filters and catalysts.

\section{Results}

\subsection{Pycnometry}

Table 2 documents the results of the pycnometry experiments in the first seven numerical columns. The average results, calculated for 3 replicate runs for each sample, as well as the instrumental relative standard deviations (RSDs) of the measurements are given. Open pore volume $\phi_{\mathrm{OPV}}$, closed pore volume $\phi_{\mathrm{CPV}}$ and total porosity $\phi_{\text {tot }}$ were calculated from helium and powder volume displacement, and from a value of graphite crystal density of $2.26 \mathrm{~g} \mathrm{~cm}^{-3}$. It can be seen that the bulk density measurements are in good agreement with those provided by the manufacturer (Table 1). IG-110 has a slightly larger total porosity, which comprised a lower $\phi_{\mathrm{OPV}}$ and higher $\phi_{\mathrm{CPV}}$ when compared to IG-430.

\subsection{Gas adsorption}

High resolution $\mathrm{N}_{2}$ isotherms were obtained for each sample, Figure 1. The three replicate readings sit on top of each other showing a high level of repeatability for the samples. IG-110 (Fig 1a) and IG-430 (Fig 1b) exhibit IUPAC 
This is the author's accepted manuscript. The final published version of this work (the version of record) is published by Elsevier in Carbon (March 2018) available at: http://doi.org/10.1016/j.carbon.2017.11.076. This work is made available online in accordance with the publisher's policies. Please refer to any applicable terms of use of the publisher.

Table 2: IG-110 and IG-430 nuclear graphite densities derived from powder and helium pycnometry, and porosities derived from pycnometry and mercury porosimetry, showing instrumental relative standard deviations (RSDs). The average envelope density was measured by powder pycnometry and average skeletal density by helium pycnometry.

\begin{tabular}{ccccccccc} 
Sample & $\begin{array}{c}\text { Average } \\
\text { skeletal } \\
\text { density }\end{array}$ & $\begin{array}{c}\text { Instrument } \\
\text { RSD } / \%\end{array}$ & $\begin{array}{c}\text { Bulk } \\
\text { Density } \\
/ \mathrm{g} \mathrm{cm}^{-3}\end{array}$ & $\begin{array}{c}\text { Instrument } \\
\text { RSD } / \%\end{array}$ & $\begin{array}{c}\text { Pycnometry } \\
\text { derived open } \\
\text { pore volume } \\
\phi_{\text {OPV }} / \%\end{array}$ & $\begin{array}{c}\text { Pycnometry } \\
\text { derived closed } \\
\text { pore volume } \\
\phi_{\mathrm{CPV}} / \%\end{array}$ & $\begin{array}{c}\text { Pycnometry } \\
\text { derived total } \\
\text { porosity } \\
\phi_{\text {tot }} \%\end{array}$ & $\begin{array}{c}\text { Hg derived } \\
\text { total } \\
\text { porosity } \\
\phi_{\mathrm{Hg}} / \%\end{array}$ \\
\hline IG-110 & 2.06 & 0.04 & 1.79 & 0.19 & 12.61 & 7.75 & 20.36 & 24.31 \\
IG-430 & 2.10 & 0.08 & 1.81 & 0.22 & 13.31 & 6.31 & 19.62 & 21.07 \\
\hline
\end{tabular}

Type II isotherms, corresponding to a non-porous or macroporous adsorbent.

A Type II isotherm represents unrestricted monolayer-multilayer adsorption.

Both graphite samples have Type H3 hysteresis loops, typically observed in samples that consist of well connected, plate-like particles which comprise of slit-shaped pores. All isotherms also show forced closure of hysteresis loop, due to a sudden drop in volume adsorbed in the $P / P_{0}$ range $0.46-0.52$, as a result of the 'tensile strength effect' of the adsorbate [62]. These results, typical for polycrystalline synthetic graphites [63], are consistent with the morphology of the samples visible in the scanning electron micrographs for the IG graphites, Figure 2 .

The $\mathrm{N}_{2}$ adsorption/desorption isotherms are very similar for the two samples, differing only in the total adsorbed volume of $\mathrm{N}_{2}$, which was significantly larger for the IG-110 graphite. All isotherms show a slight uptake of nitrogen at low relative pressures $\left(P / P_{0}<0.2\right)$, which could suggest a small percentage of microporosity within the samples. However, this step is most likely caused due to the intrinsic van der Waals interactions between the adsorbate and the ordered graphite surface [64]. The steep incline in the nitrogen adsorption isotherm observed at high relative pressures $\left(P / P_{0}>0.95\right)$ indicates a considerable presence of macroporosity, and the presence of mesoporosity is confirmed by the increase in volume over the middle pressure range $\left(0.2<P / P_{0}<0.95\right)$. Table 3 shows the surface areas calculated according to the BET and BJH approximations, where IG-110 is nearly twice that of IG-430.

PSDs were obtained using the adsorption branch of the IG graphite via GCMC simulations, Figure 3, and the classical BJH approximation, SI Figure 2. The two interpretation methods provided similar distributions for both graphites. Two separate GCMC simulations were obtained for each IG graphite; one representing cylindrical pores, the second representing slit pores. The 

(March 2018) available at: http://doi.org/10.1016/j.carbon.2017.11.076. This work is made available online in accordance with the publisher's policies. Please refer to any applicable terms of use of the publisher.
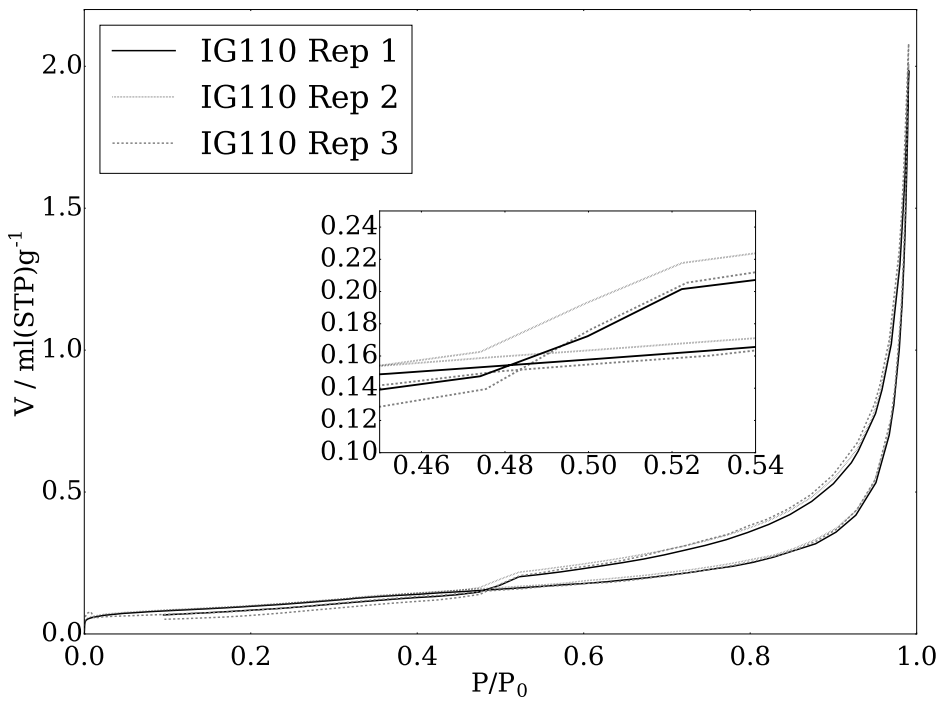

(a)

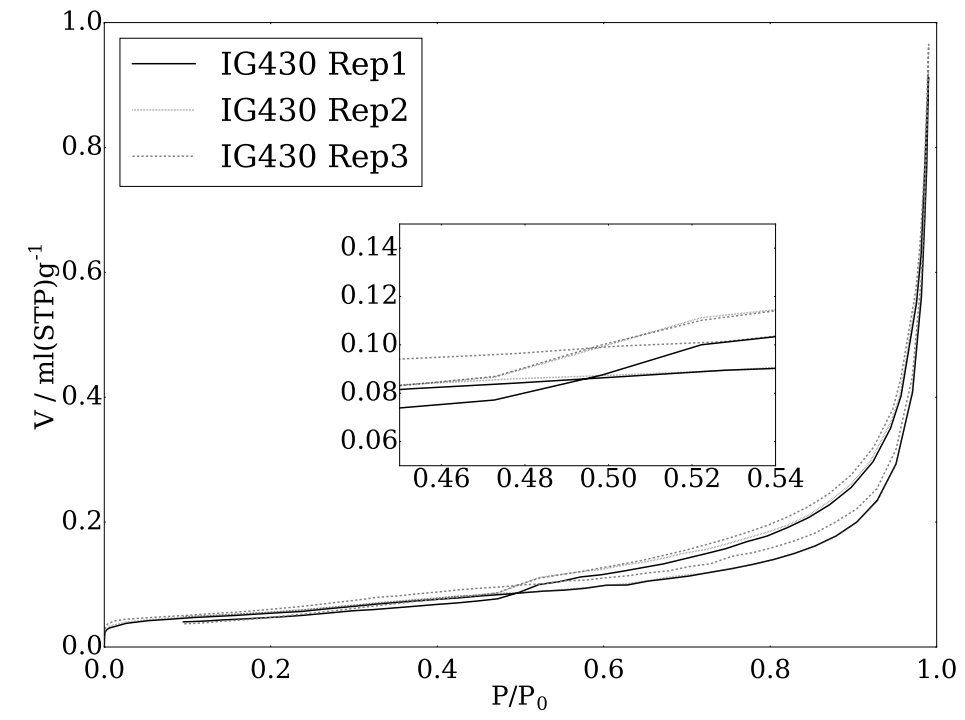

(b)

Figure 1: High resolution $\mathrm{N}_{2}$ adsorption/desorption isotherms at $77.35 \mathrm{~K}$ for IG nuclear graphites with magnified views displaying the forced closure of the hysteresis; (a) Replicate isotherms for IG-110 (b) Replicate isotherms for IG-430

cylindrical shape approximation, covering the size range 0.4 to $565 \mathrm{~nm}$, is the same as that used for mercury porosimetry via equation (1), whereas the second, 
This is the author's accepted manuscript. The final published version of this work (the version of record) is published by Elsevier in Carbon (March 2018) available at: http://doi.org/10.1016/j.carbon.2017.11.076. This work is made available online in accordance with the publisher's policies. Please refer to any applicable terms of use of the publisher.

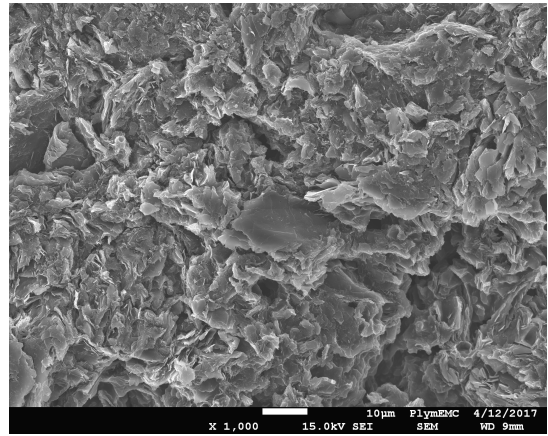

(a)

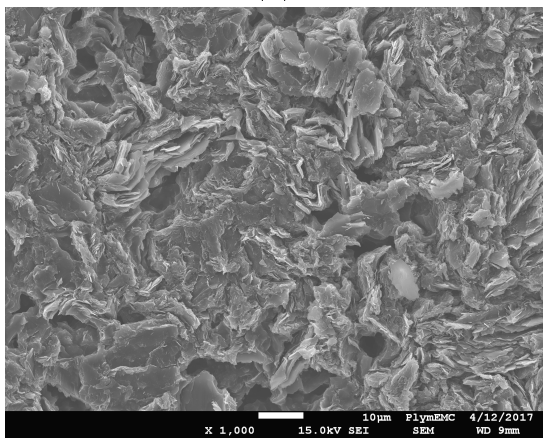

(c)

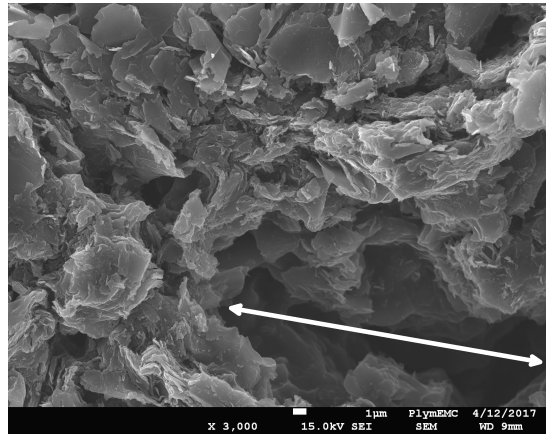

(b)

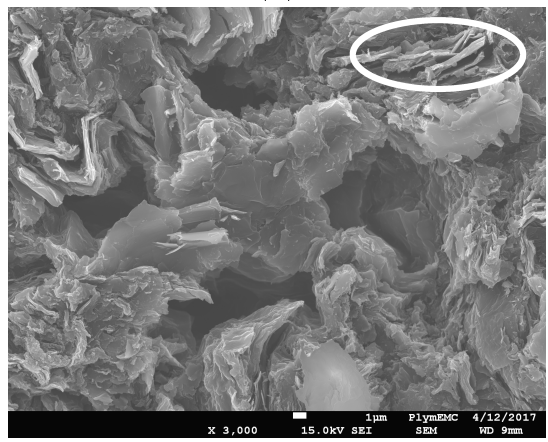

(d)

Figure 2: Scanning electron micrographs of virgin IG nuclear graphites (a) IG-110 x1000 magnification (b) IG-110 x3000 magnification, large slit pore shown by the arrow; (c)IG-430 x1000 magnification (d) IG-430 x3000 magnification, smaller slit shaped pores shown by the ellipse. The scale bars, shown in white at the bottom of the images, are equal to $10 \mu \mathrm{m}$ for figures a and $\mathrm{c}$ and $1 \mu \mathrm{m}$ for figures $\mathrm{b}$ and $\mathrm{d}$.

Table 3: The average specific surface areas derived from BET and BJH interpretations, and the total pore volumes calculated by the GCMC simulations for IG-110 and IG-430 nuclear graphite. Additionally, average open pore volume has been calculated. Results in this table represent the average value calculated from three replicate analyses.

\begin{tabular}{ccccc} 
Sample & $\begin{array}{c}S_{\mathrm{BET}} \\
\mathrm{m}^{2} \mathrm{~g}^{-1}\end{array}$ & $\begin{array}{c}S_{\mathrm{BJH}} \\
\mathrm{m}^{2} \mathrm{~g}^{-1}\end{array}$ & $\begin{array}{c}V_{\mathrm{GCMCCyl}} \\
\mathrm{cm}^{3} \mathrm{~g}^{-1}\end{array}$ & $\begin{array}{c}V_{\mathrm{GCMC} \mathrm{Slit}} \\
\mathrm{cm}^{3} \mathrm{~g}^{-1}\end{array}$ \\
\hline IG-110 & 0.37 & 0.35 & $1.30 \times 10^{-3}$ & $2.90 \times 10^{-3}$ \\
IG-430 & 0.22 & 0.19 & $6.99 \times 10^{-4}$ & $1.35 \times 10^{-3}$ \\
\hline
\end{tabular}

in the range 0.4 to $92 \mathrm{~nm}$, is more representative to the actual shapes of the voids, as seen in Figure 2. The relative results for IG-110 and IG-430 are in accord with the isotherm observations and overall surface area results described earlier. Both geometrical simulations display the same trend for both IG graphites, but it can be seen that the total pore volumes (shown in Table 3) for the slit simulations were twice as large as the cylindrical simulations. 

(March 2018) available at: http://doi.org/10.1016/j.carbon.2017.11.076. This work is made available online in accordance with the publisher's policies. Please refer to any applicable terms of use of the publisher.

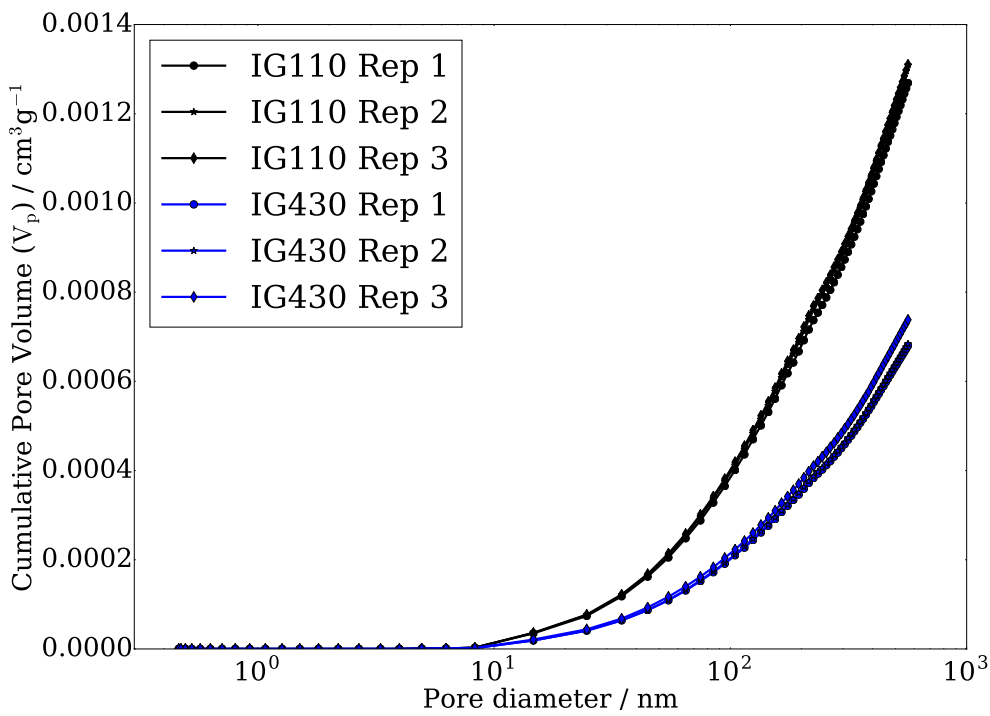

(a)

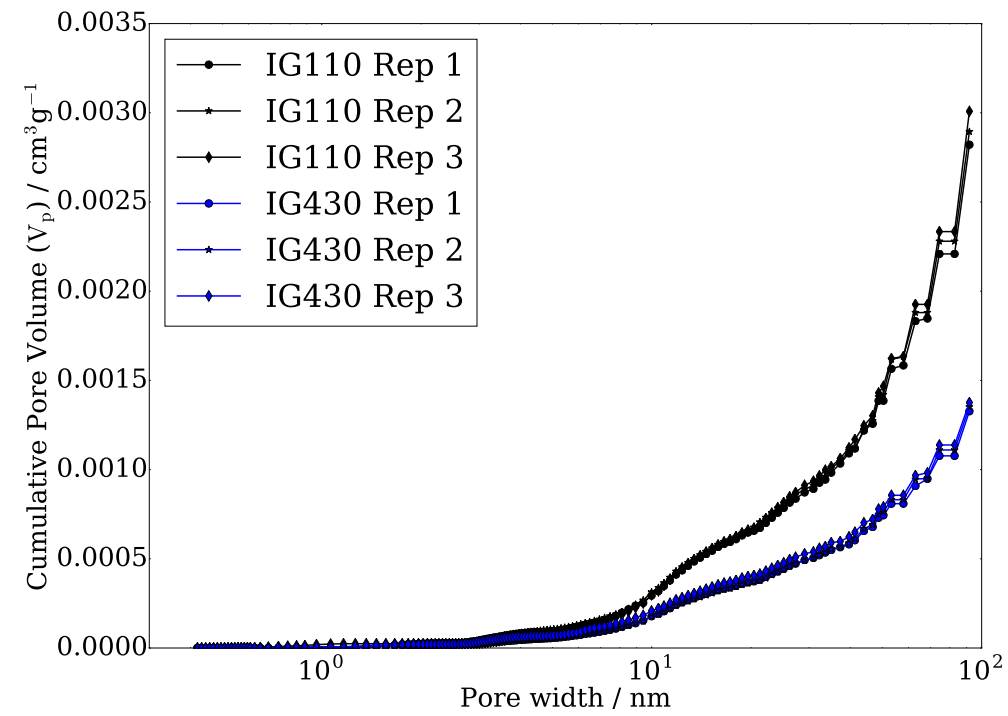

(b)

Figure 3: Cumulative PSDs obtained using GCMC modelling simulations of the gas adsorption data for IG nuclear graphites. (a) Replicate simulations for cylindrical shaped pores and (b) slit shaped pores.

\subsection{Mercury porosimetry}

The consecutive porosimetry curves for each graphite are shown in Figures 4a and $4 \mathrm{~b}$, over a pressure range of 0.0165 to $400 \mathrm{MPa}$ corresponding to size ranges, 
This is the author's accepted manuscript. The final published version of this work (the version of record) is published by Elsevier in Carbon (March 2018) available at: http://doi.org/10.1016/j.carbon.2017.11.076. This work is made available online in accordance with the publisher's policies. Please refer to any applicable terms of use of the publisher.

via equation 1, of 89 to $0.00367 \mu \mathrm{m}$. The first intrusion curves, represented by the continuous lines, follow a traditional sigmoidal trend at low pressure. However, at pressures around 0.8-0.9 MPa the slope of this curves suddenly changes and, from that point onwards, the amount of mercury intruding the samples continues to increase with pressure. This behaviour is very different from the mercury intrusion curves traditionally encountered when analysing other materials, which plateau at high pressure. Upon depressurisation only $10 \%$ of the previously intruded mercury exited the void structure by capillary expulsion forces, whilst the majority of the mercury remained trapped within the complex void network post depressurisation (SI Table 1).

In order to investigate the level of damage and deformation caused to the microstructure of the samples during the first porosimetry run, consecutive analyses were performed. Prior to the second analysis, samples were heated in vacuo in order to remove as much of the residual mercury trapped in the internal void system left over from the previous analysis. However, it was found that a small percentage of the intruded mercury, around 3-5\%, was retained permanently by the structure post thermal treatment. This residual trapped mercury is thought to contribute to the reduced total intrusion volumes observed for the consecutive runs (Figure 4). Such a phenomenon is consistent with historical data which observed this permanent retention of mercury for all grades of graphite [48]. The exact volumes of mercury present within the samples at three key stages of the analysis (maximum intrusion volumes for the first porosimetry runs, retained volumes of mercury post depressurisation of the first porosimetry runs and permanently retained volumes of mercury post thermal treatment) can be found in the SI Table 1.

The consecutive porosimetry runs demonstrate that the damage and deformation to the graphite's microstructure caused by the mercury porosimetry at high pressure affect the results of the second porosimetry run, for both graphites, displaying a slight reduction in total porosity. The damage most likely occurred during the highest pressures of the mercury intrusion on the first intrusion, but the effects of the damage can be seen at every pore size on the second intrusion. Comparison of the consecutive intrusion curves shows the destruction was mainly of the largest void features, as lack of intrusion at the lowest 
This is the author's accepted manuscript. The final published version of this work (the version of record) is published by Elsevier in Carbon (March 2018) available at: http://doi.org/10.1016/j.carbon.2017.11.076. This work is made available online in accordance with the publisher's policies. Please refer to any applicable terms of use of the publisher.

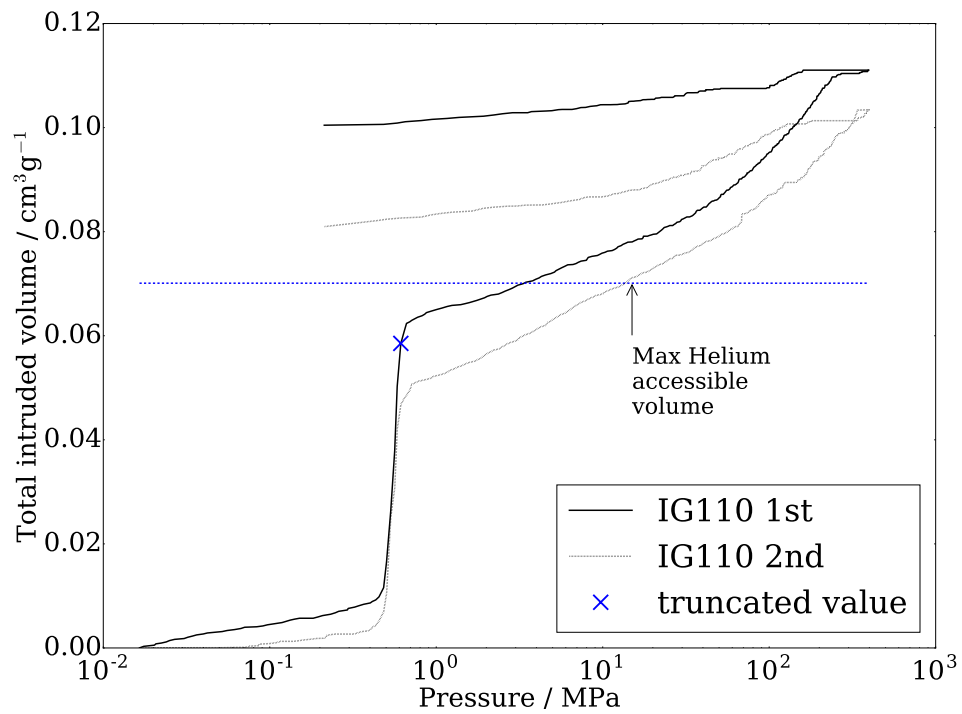

(a)

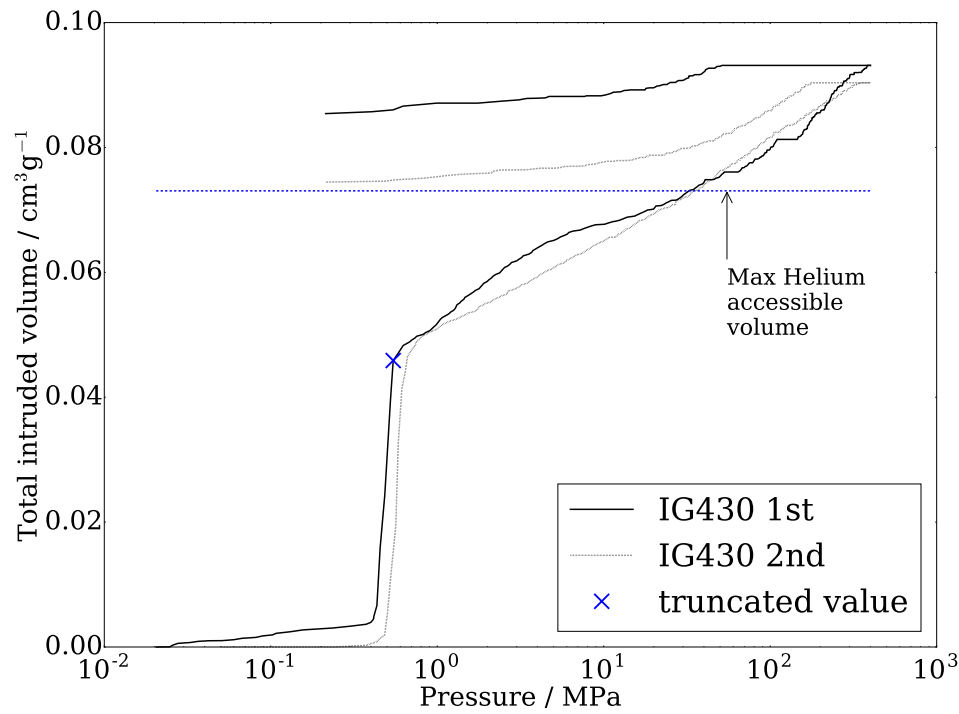

(b)

Figure 4: Consecutive porosimetry curves for (a) IG-110 (b) IG-430. Also shown is the maximum helium accessible volume for both graphites, which is, in both cases, significantly lower than the apparently accessed volume achieved by mercury. The point at which the first percolation curve was truncated, due to unreliability of higher pressure data, is also marked.

pressures in the second runs showed that these had become almost completely absent. By contrast, the intermediate and high pressure regions of the curves 
This is the author's accepted manuscript. The final published version of this work (the version of record) is published by Elsevier in Carbon (March 2018) available at: http://doi.org/10.1016/j.carbon.2017.11.076. This work is made available online in accordance with the publisher's policies. Please refer to any applicable terms of use of the publisher.

behaved similarly in both runs. This suggest that little damage occurred to the void features corresponding to the steep part of the mercury intrusion curve, 2 to $4 \mu \mathrm{m}$ range. However, in both consecutive runs the intrusion curves show the change in slope described above, and mercury intrusion does not tail off even at the highest pressure. This strange behaviour has led to concerns in the literature over porosimetry's applicability for graphite. Possible explanations for the behaviour are described in the Discussion section. However, it is largely accepted that if the mercury intrusion curve indicates a substantial presence of pores below $0.1 \mu \mathrm{m}$, caution should be exercised on the credibility of the results [48]. Additionally, other studies found that should the porosity obtained from mercury porosimetry be larger than that obtained by He-pycnometry, as is the case for the IG graphites, it is advised that data points above a critical porosimetry pressure should be disregarded. Studies found that for many graphites this critical pressure is between 13-20 MPa [47] which implies that data after the main intrusion peak for the IG graphites is difficult to interpret. In our case, this conclusion could be extended to the intrusion data obtained for pressures greater than $0.5-0.6 \mathrm{MPa}$, at which the initial change in the slope of the steep section of the intrusion curve takes place.

\subsection{Modelling}

As described above, the high pressure portion of the mercury intrusion curve is unreliable for graphite, and therefore, the percolation curve from the first intrusion run (prior to thermal treatment) was truncated at the last experimental point before the second derivative of intrusion with respect to pressure becomes negative (i.e. before the slope change). Exact values were 0.61 MPa and $0.54 \mathrm{MPa}$, corresponding to total intruded volumes of $53.58 \mathrm{~mm}^{3} \mathrm{~g}^{-1}$ and $48.88 \mathrm{~mm}^{3} \mathrm{~g}^{-1}$ for IG-110 and IG-430 respectively, and can been identified in Figures $4 \mathrm{a}$ and $4 \mathrm{~b}$. The portion of the percolation curves derived from the first mercury intrusion porosimetry analysis corresponds to an equivalent Laplace diameter range of $2-89 \mu \mathrm{m}$. No pore size information was used from the second porosimetry run, which was only utilized to determine the pressure beyond which structural damage and deformation resulted in unreliable porosimetry data.

In order to overcome the shortcomings of the mercury porosimetry exper- 
This is the author's accepted manuscript. The final published version of this work (the version of record) is published by Elsevier in Carbon (March 2018) available at: http://doi.org/10.1016/j.carbon.2017.11.076. This work is made available online in accordance with the publisher's policies. Please refer to any applicable terms of use of the publisher.

imental procedure, the high-pressure portion of the mercury intrusion curve was replaced, and ultimately extended, by using the void volume estimates produced by GCMC simulations of gas adsorption characteristics. In order to make porosimetry and GCMC results compatible, only the results of the GCMC simulations with cylindrical pores were used, and the void volume results were converted to the equivalent intrusion characteristics. The total intrusion volume for each sample was set at the maximum He-accessible volume, $70.04 \mathrm{~mm}^{3} \mathrm{~g}^{-1}$ for IG-110 and $73.27 \mathrm{~mm}^{3} \mathrm{~g}^{-1}$ for IG-430, as this best reflects the open pore volume for each of the IG graphites.

Rather than arbitrarily stitch the two curves together, we recognise that there is a gap between them, Figure 5. A useful feature of the pore network simulation software PoreXpert is that it does not require the entire range of percolation data at all pressures. Instead, if data points are missing, it attempts to guess the percolation characteristics. The stochastic nature of the modelling results in increased gaps in the data being reflected in increased differences within a series of stochastic generations.

Five stochastic generations were generated for the combined percolation characteristics of both IG graphites. The structures chosen as most representative of the samples were those that had all five fitting parameters, described above, closest to the mean of those parameters (shown bold in SI Table 2). Complete cumulative void volume distributions generated by the most representative fittings are shown by Figure 5. Additionally, the mercury porosimetry branch of the differential void volume distribution grossly underestimates the void sizes, as explained in the Introduction, but is included for completeness.

$3 \mathrm{D}$ simulated pore networks were generated for the representative structures, Figure 6, for further analysis. The networks are non-hierarchical - i.e. all voids act in a concert in a single network, rather than acting discretely according to size as in, for example, the "two pore" model [65]. This allows a more realistic calculation of the relative network flow capacities of the two samples, which trend with, but are smaller than, the absolute permeabilities [66]. Results showed that IG-110 displays a higher network flow capacity, $9.18 \times 10^{-18} \mathrm{~m}^{2}$, compared to IG-430, $5.53 \times 10^{-18} \mathrm{~m}^{2}$. Understanding the network flow capacity of virgin materials is the first step towards a detailed quantitative evaluation 

(March 2018) available at: http://doi.org/10.1016/j.carbon.2017.11.076. This work is made available online in accordance with the publisher's policies. Please refer to any applicable terms of use of the publisher.

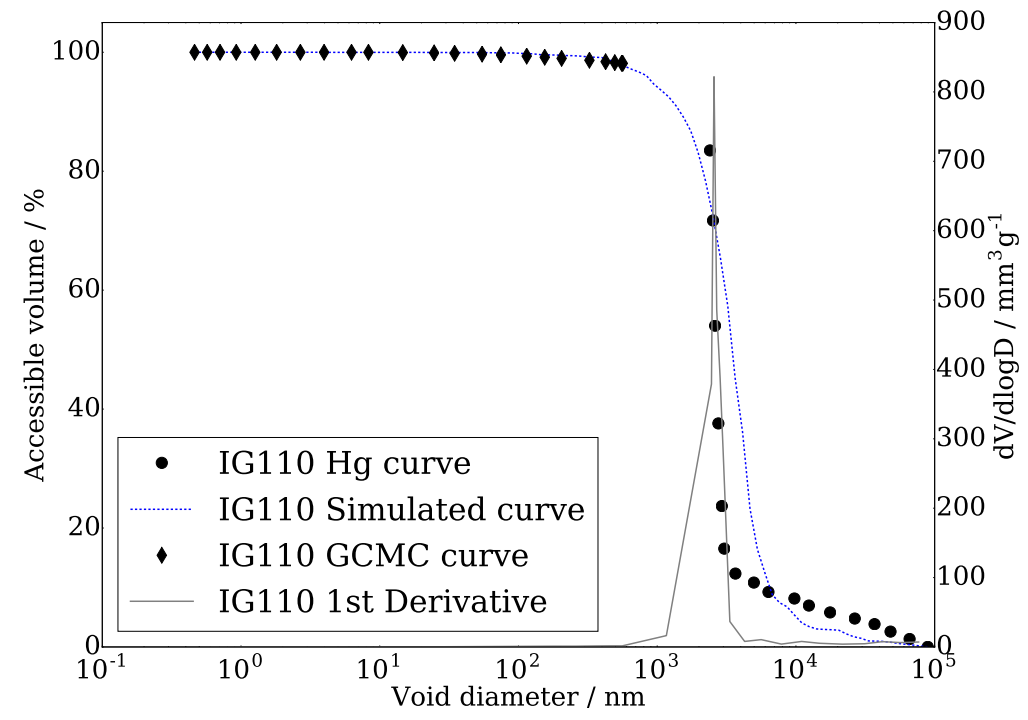

(a)

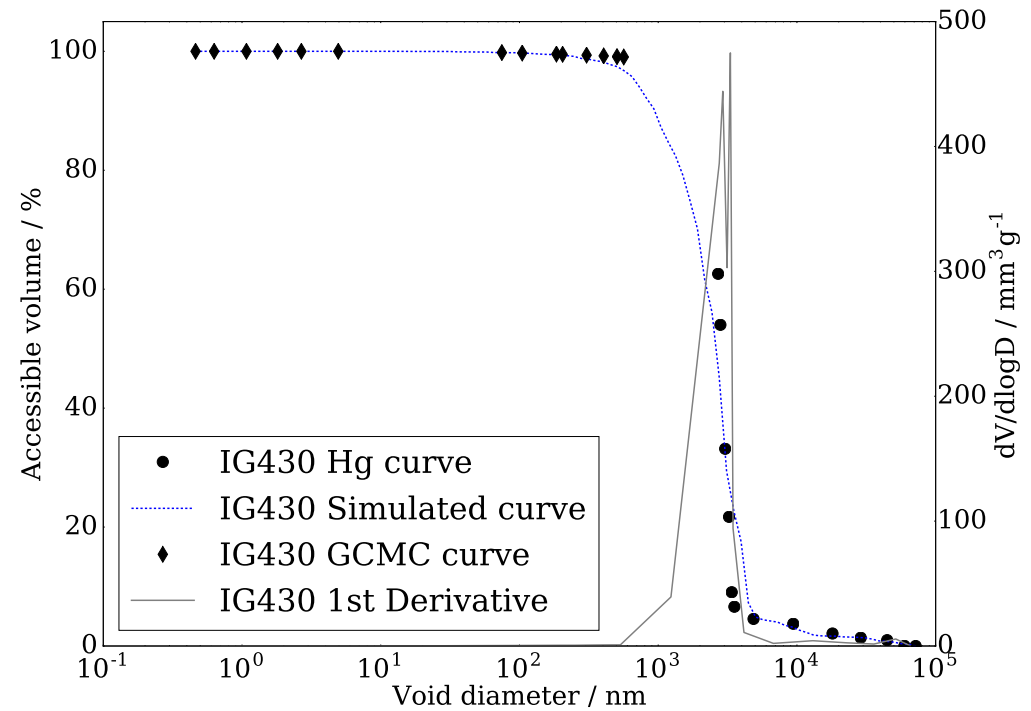

(b)

Figure 5: Multi-technique (combined GCMC, truncated mercury porosimetry and simulated data) cumulative and differential distribution of void sizes for IG nuclear graphites, with intrusion expressed as percentage of surface-accessible void volume; (a) IG-110 (b) IG-430

of the presence of preferential flow paths and of the dwell time of chemical species in the void features, which are some of the factors contributing to 
This is the author's accepted manuscript. The final published version of this work (the version of record) is published by Elsevier in Carbon (March 2018) available at: http://doi.org/10.1016/j.carbon.2017.11.076. This work is made available online in accordance with the publisher's policies. Please refer to any applicable terms of use of the publisher.

the outcomes of thermal oxidation to be studied both experimentally and via simulation modifications in future projects.

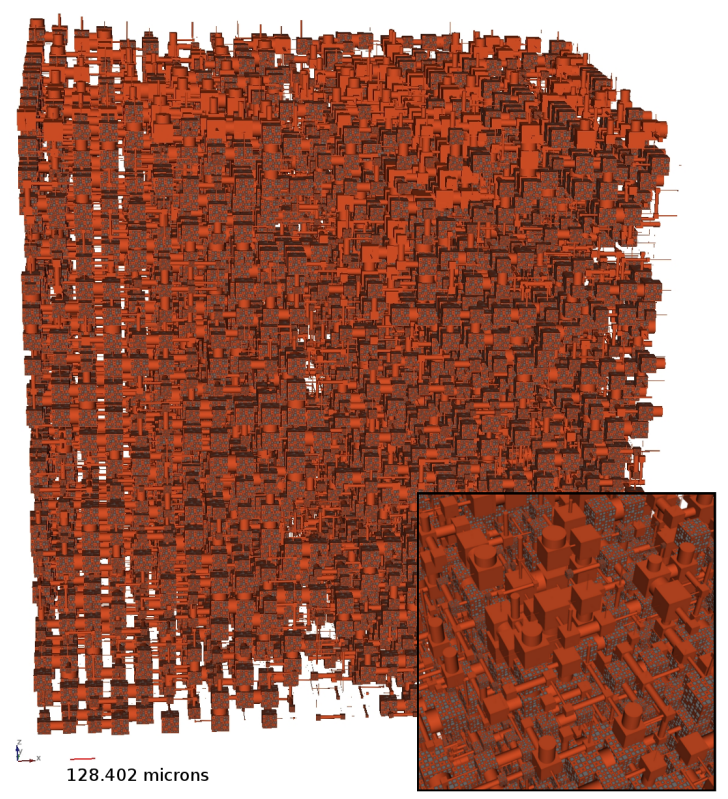

(a)

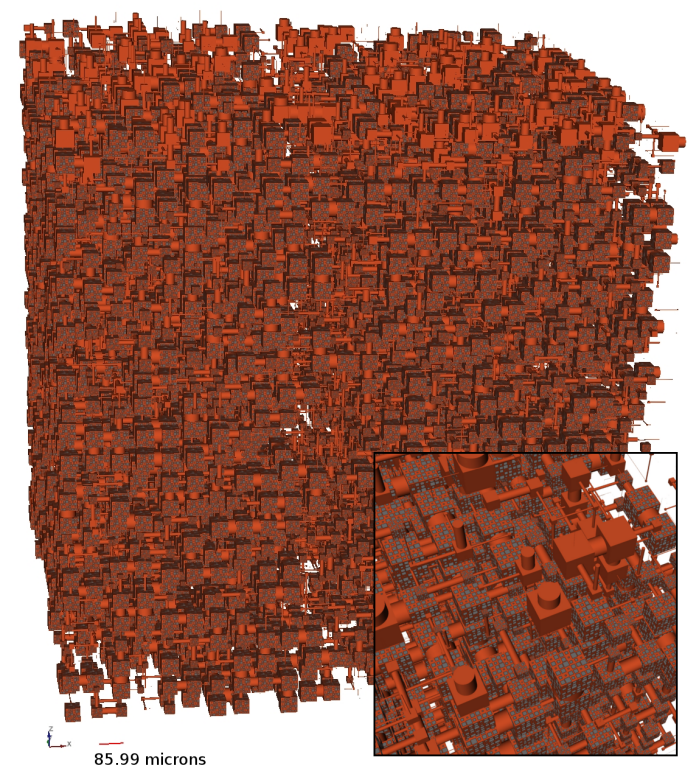

(b)

Figure 6: 3D simulated pore networks for IG nuclear graphites; (a) IG-110 (b) IG-430. The darker textured surfaces show possible positions of void clusters undifferentiated by the mercury porosimetry. Small scale bars are (a) 128.4 and (b) $85.99 \mu \mathrm{m}$. 
This is the author's accepted manuscript. The final published version of this work (the version of record) is published by Elsevier in Carbon (March 2018) available at: http://doi.org/10.1016/j.carbon.2017.11.076. This work is made available online in accordance with the publisher's policies. Please refer to any applicable terms of use of the publisher.

Simulated PSDs, displayed as both cumulative void volumes and percentage number of voids features against void size, generated by the modelling software PoreXpert for the two IG graphites can be viewed in Figure 7 .

\section{Discussion}

While the accessible porosity of IG-430 is marginally greater than that of IG-110, as shown by the maximum intrusion volumes in Figure 4, the mercury intrusion curve of IG-110 shows a steeper gradient in the lower pressures region. This can be interpreted as presence of a larger volume of the largest void features ( $23 \mu \mathrm{m})$.

The overall shape of the intrusion curve, which fails to plateau at the highest pressures, is distinctive of graphite [47, 48, 50]. In previous work [50], the authors explained some of the peculiarities of the high pressure region of mercury intrusion curves of graphite and concluded that they do not represent actual intrusion of void space. This is supported by four observations. Firstly, there is a discrepancy with the helium pycnometry results; Figure 4 shows that the volume accessible to mercury is apparently much greater than that accessible to helium. Secondly, the smoothness of the graphite surfaces shown in Figures $2 \mathrm{~b}$ and $2 \mathrm{~d}$ indicates an absence of sub-micron pores. Thirdly, via the Laplace equation (1), the highest mercury intrusion pressure should intrude voids of around 3.7 $\mathrm{nm}$ in diameter, whereas the GCMC analysis suggest that there is a negligible volume of voids below $8 \mathrm{~nm}$. Finally, if the continuously increasing intrusion was explainable by compression of the graphite, then the extent of compression should correspond to the Young's moduli of the samples, 9.8 and $10.8 \mathrm{GPa}$, Table 1. Since these are normally measured uni-axially, whereas mercury compresses tri-axially, we would expect the apparent tri-axial bulk moduli to be higher than uni-axial Young's moduli. The observed intrusion above the point of negative second derivative is around $50 \mathrm{~mm}^{3} \mathrm{~g}^{-1}$ which corresponds to a bulk modulus of around $13 \mathrm{GPa}$ (SI Table 3), in agreement with the manufacturer's data. It is possible that the graphite crystallites, randomly oriented within the sample, are elastically compressed under the pressures applied to the mercury. However, elastic compression should result in an extrusion curve which tracks back down the intrusion curve as the pressure is released and the sample re-expands, 
This is the author's accepted manuscript. The final published version of this work (the version of record) is published by Elsevier in Carbon (March 2018) available at: http://doi.org/10.1016/j.carbon.2017.11.076. This work is made available online in accordance with the publisher's policies. Please refer to any applicable terms of use of the publisher.

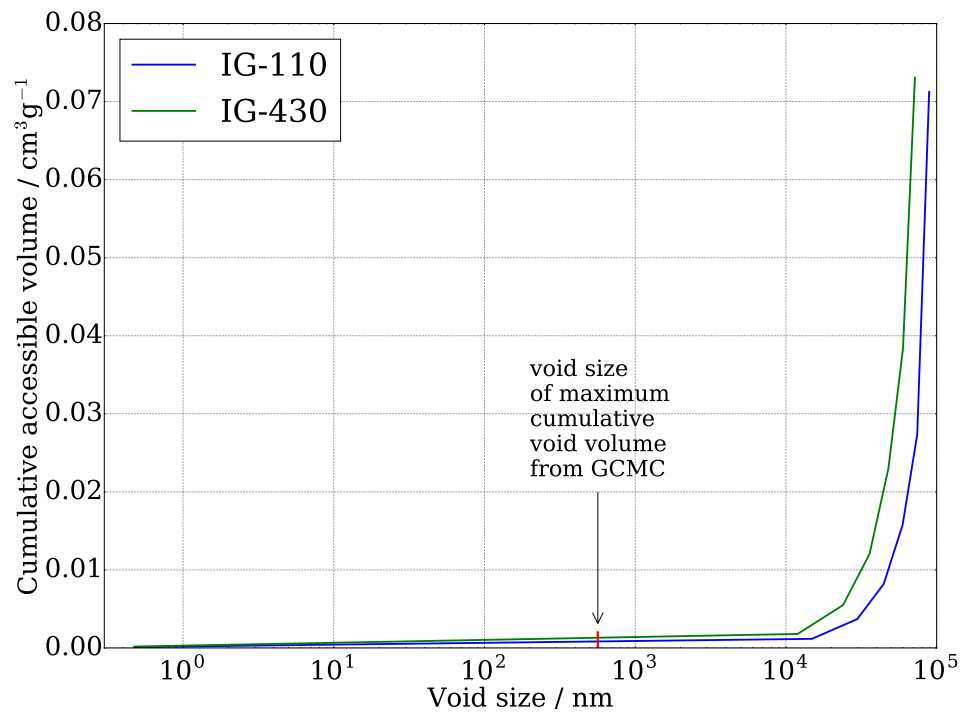

(a)

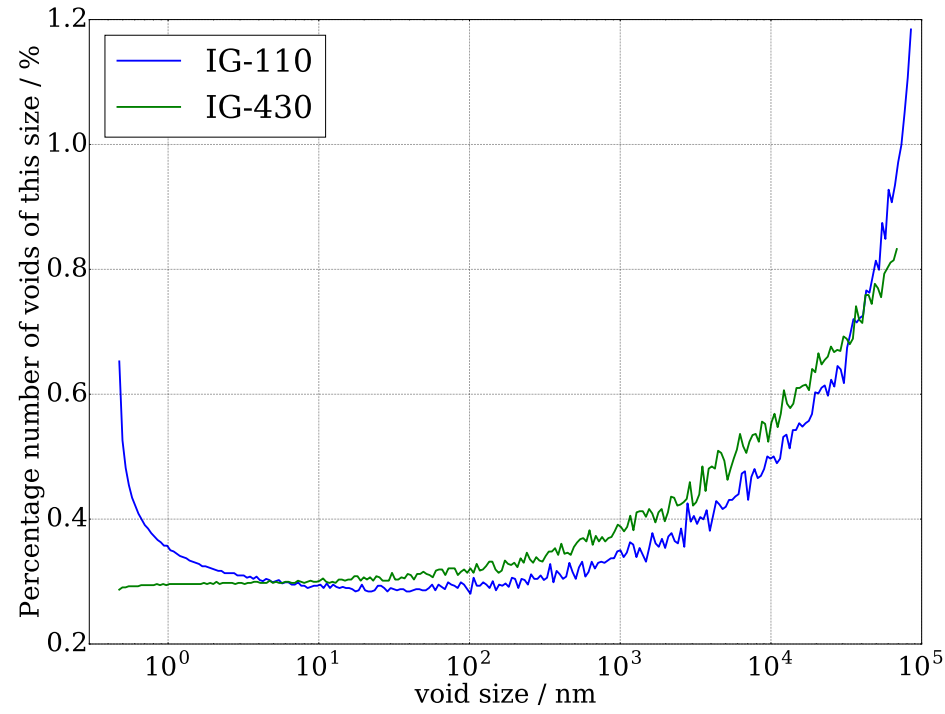

(b)

Figure 7: Simulated PSD for IG nuclear graphites expressed as (a) cumulative pore volume and (b) percentage number of voids of a given size against void size. These are obtained from the simulated 3D void networks, generated by the modelling software using the multi-technique combined void size information.

whereas it can be seen in Figures $4 \mathrm{a}$ and $4 \mathrm{~b}$ that much of the mercury stays trapped until it is removed via thermal treatment. At the same time, the solid 
This is the author's accepted manuscript. The final published version of this work (the version of record) is published by Elsevier in Carbon (March 2018) available at: http://doi.org/10.1016/j.carbon.2017.11.076. This work is made available online in accordance with the publisher's policies. Please refer to any applicable terms of use of the publisher.

structures are potentially being damaged in a way similar to that described by Liu et al. [67], with solid phase features snapping and rearranging in a 'bridging' phenomenon that could explain both the continuously increasing amount of intruded mercury as well as the trapping of mercury within the void structure even after thermal and vacuum treatment of the samples. Nevertheless, the precise mechanism of what is occurring remains unresolved.

The extrusion curves for the graphites demonstrate a high proportion of trapped mercury within the microstructure after depressurisation. Complexity within the interconnected void network will contribute to mercury snap off and therefore, the retention of mercury within certain pores. Due to the extent of residual mercury retained by both graphites, it can be postulated that the porous network comprises larger pores interconnected by smaller pore-throats [50]. This was reflected by the generated 3D structures in Figure 6 which displayed a random orientation of the pores and throats compared to a banded, natural arrangement.

Mercury that was permanently retained by the structure, even after thermal and vacuum treatment, can be explained by elastic deformation of the graphite at high operating pressures. The extreme pressures utilised during porosimetry can cause small amounts of previously inaccessible pores to become temporarily accessible, and are therefore filled with mercury. Upon depressurisation the newly formed entrances within the graphite layers relax, permanently closing off the pore to the network and encasing the mercury within the graphite sample.

When comparing the total porosities obtained from the two experimental techniques, it is noted that larger values of total porosity were achieved from mercury porosimetry than from pycnometry. Whilst this relationship is not uncommon, due to the destructive nature of porosimetry analysis, the proportion of the discrepancy, visible in Table 2, differs slightly for the two graphites: a $4 \%$ excess for IG-110 compared to $1.4 \%$ excess for IG-430. It is proposed that the increased tensile strength of IG-430 provided some protection against structural damage to pore walls, which prevented access to surrounding closed porosity. Additionally, when truncating the data, a lower critical pressure than previous literature suggested (13-20 MPa)[47] was used. It was found that, for the IG graphites, the critical pressure range exceeded the helium intrusion volume and 
This is the author's accepted manuscript. The final published version of this work (the version of record) is published by Elsevier in Carbon (March 2018) available at: http://doi.org/10.1016/j.carbon.2017.11.076. This work is made available online in accordance with the publisher's policies. Please refer to any applicable terms of use of the publisher.

therefore, a more suitable end point described throughout the Results section was used.

Gas adsorption measurements confirm that IG-110 has a larger accessible surface area than IG-430, Table 3 . The PSDs, obtained from GCMC simulations on the adsorption isotherms, are expressed as cumulative void volumes in Figure 3. They show significant void volumes in the range 8 to $500 \mathrm{~nm}$, and indicate that IG-110 has around twice the volume of these small features compared to IG-430 over the entire range of pore sizes probed. This is in agreement with a material containing a larger proportion of smaller pores (IG-110 in this case) having a larger specific surface area. Table 3 also shows that both the BET and BJH surface areas are very similar for each sample. Since the BET approach allows for multi-layer adsorption, and the BJH approach allows for Kelvin condensation, the results support the conclusion that there is no microporosity in either sample type.

The combination of the data from mercury intrusion porosimetry, up to the onset of the gradient change on the steep part of the curve, with the cumulative void volume generated by GCMC simulation of gas adsorption data, generates percolation characteristics which avoid many of the shortcomings usually associated with the characterization of graphite PSD. Whilst the volume contribution of pores below $500 \mathrm{~nm}$ (from GCMC simulations) to the overall void volume of the samples is minimal, as shown by the arrow in Figure 7a, its inclusion is necessary to correct the false information otherwise obtained in the high-pressure region of the mercury intrusion data. It is also noted that the PSD contributed by the low pressure gas adsorption utilized by the modelling software could underestimate the total pore volumes due to the geometrical model used (i.e. cylinders rather than slits). However, the volume difference between each geometrical type was found to be negligible in the context of the overall percolation curves of both IG graphites.

The modelling of these percolation characteristics by means of a void network simulation software resulted in a representation of the pore network of the two graphites, that, despite being very simplistic in its geometry, manages to capture some important properties of the samples. In particular, it can be noticed that the modelled structures have very low values for the correlation level $\mathscr{C}$ 
This is the author's accepted manuscript. The final published version of this work (the version of record) is published by Elsevier in Carbon (March 2018) available at: http://doi.org/10.1016/j.carbon.2017.11.076. This work is made available online in accordance with the publisher's policies. Please refer to any applicable terms of use of the publisher.

(0.01 and 0.05 for IG-110 and IG-430 respectively), indicating a very random void structure with no local size auto correlation, which is consistent with the manufacturing method of IG graphites and with the qualitative information that can be gathered from the SEM images presented in Figure 2. This random arrangement of the pores also controls the network flow capacity for the IG graphites. It was seen in Section 4.4 that IG-430 has a smaller capacity, which is consistent with the fact that IG-430 is the denser of the two materials and the one showing a lower volume of the largest permeability-controlling voids, Figure 7b. Additionally, the simulated PSDs in Figure 7b show that IG-430, in agreement with the surface characteristics discussed above, has a lower number of the smallest surface void features. This is the portion of the cumulative void size distribution that is probed by gas adsorption. Despite the presence of a large peak for IG-110, the overall contribution of these smaller voids to the total void volume is minimal, which is evident in Figure 7a, where the volumetric contribution of the smallest voids is indistinguishable for both graphites.

Both graphites show a peak in the simulated distributions, both in terms of number of void features and in terms of volume, at the size of the largest feature. This does not signify that the samples present a large number of large voids all of the same size, but instead it corresponds to unresolved clusters of voids, probed by mercury at pressures much larger than their corresponding Laplace pressure. The possible positions of these clusters are shown textured in Figure 6 .

\section{Conclusions}

Historically, the anomalous intrusion of graphite by mercury at high pressure has prevented the use of porosimetry to give a quantitative void network model for graphite. Other analytical techniques also suffered from various shortcomings. The multi-experimental approach introduced in this work overcomes many of these issues and it is able to produce a representation of whole range of pore sizes for unirradiated IG-110 and IG-430. Results suggest that these two grades of nuclear graphite are highly comparable, and in most respects, they show very similar pore-level properties. However, differences in the manufacturing process, such as the coking material used, have resulted in slightly different microstruc- 
This is the author's accepted manuscript. The final published version of this work (the version of record) is published by Elsevier in Carbon (March 2018) available at: http://doi.org/10.1016/j.carbon.2017.11.076. This work is made available online in accordance with the publisher's policies. Please refer to any applicable terms of use of the publisher.

tural properties for the two graphites. Once modelled, these differences yield different network flow capacities, which could potentially lead to distinctive evolution of the surface and void network properties of the two graphites in an oxidative environment.

We also plan to adopt the same approach for the study of another grade of nuclear graphite, Gilsocarbon, used in the UK's fleet of Advanced gas cooled reactors (AGRs). By fully characterizing the void space of unirradiated samples and samples that have undergone an irradiation and radiolytic oxidation campaign, we aim to gain an insight into the ageing of Gilsocarbon, which is an essential parameter for the safe extension of the AGR's operating lifetime. 

publisher's policies. Please refer to any applicable terms of use of the publisher.

\section{Acknowledgements}

The financial support and advice of EDF Energy (Barnwood, Gloucester, UK) is gratefully acknowledged. However, the views expressed in this paper are those of the authors and do not necessarily represent the views of the sponsors. The authors would also like to thank the University of Plymouth Electron Microscopy Centre.

\section{Appendix A. Supplementary materials}

Supplementary data associated with this article can be found in the on-line version at ...

\section{References}

[1] D. De Halas, R. Nightingale, Nuclear Graphite, Academic Press, New York (1962) 195.

[2] T. Allen, J. Busby, M. Meyer, D. Petti, Materials challenges for nuclear systems, Materials Today 13 (12) (2010) 14 - 23, ISSN 1369-7021, doi: http://doi.org/10.1016/S1369-7021(10)70220-0.

[3] K. L. Murty, I. Charit, Structural materials for Gen-IV nuclear reactors: Challenges and opportunities, J. Nucl. Mater. 383 (1-2) (2008) 189-195, ISSN 0022-3115, doi:10.1016/j.jnucmat.2008.08.044, international Conference on the Advances in Nuclear Materials, Bhabha Atom Res Ctr, Bombay, INDIA, DEC 12-14, 2006.

[4] C. Karthik, J. Kane, D. P. Butt, W. E. Windes, R. Ubic, Microstructural Characterization of Next Generation Nuclear Graphites, Microsc Microanal 18 (2) (2012) 272-278, ISSN 1431-9276, doi:10.1017/S1431927611012360.

[5] B. Kelly, T. Burchell, Structure-related property changes in polycrystalline graphite under neutron irradiation, Carbon 32 (3) (1994) 499 - 505, ISSN 0008-6223, doi:http://dx.doi.org/10.1016/0008-6223(94)90172-4.

[6] T. Burchell, J. Strizak, The effect of neutron irradiation on the fracture toughness of graphite, Nuclear Engineering and Design 271 (2014) $262-$ 269, ISSN 0029-5493, doi:http://doi.org/10.1016/j.nucengdes.2013.11.046. 

publisher's policies. Please refer to any applicable terms of use of the publisher.

[7] A. A. Campbell, Y. Katoh, M. A. Snead, K. Takizawa, Property changes of G347A graphite due to neutron irradiation, Carbon 109 (2016) 860 - 873, ISSN 0008-6223, doi:http://doi.org/10.1016/j.carbon.2016.08.042.

[8] C. Karthik, J. Kane, D. P. Butt, W. E. Windes, R. Ubic, Neutron irradiation induced microstructural changes in NBG-18 and IG-110 nuclear graphites, Carbon 86 (2015) 124 - 131, ISSN 0008-6223, doi: http://doi.org/10.1016/j.carbon.2015.01.036.

[9] B. J. Marsden, M. Haverty, W. Bodel, G. N. Hall, A. N. Jones, P. M. Mummery, M. Treifi, Dimensional change, irradiation creep and ther$\mathrm{mal} /$ mechanical property changes in nuclear graphite, INTERNATIONAL MATERIALS REVIEWS 61 (3) (2016) 155-182, ISSN 0950-6608, doi: $10.1080 / 09506608.2015 .1136460$.

[10] G. B. Neighbour, Modelling of dimensional changes in irradiated nuclear graphites, Journal of Physics D: Applied Physics 33 (22) (2000) 2966.

[11] M. R. Bradford, A. G. Steer, A structurally-based model of irradiated graphite properties, J. Nucl. Mater. 381 (1-2) (2008) 137-144, ISSN 0022-3115, doi:10.1016/j.jnucmat.2008.07.040, 8th International Graphite Specialists Meeting (INGSM-8), Sun City, SOUTH AFRICA, SEP 09-12, 2007.

[12] J. Gao, W. Yao, Y. Ma, Analytical and numerical study of graphite IG110 parts in advanced reactor under high temperature and irradiation, Nuclear Engineering and Design 305 (2016) 421 - 432, ISSN 0029-5493, doi:http://doi.org/10.1016/j.nucengdes.2016.06.014.

[13] T. Trevethan, M. Heggie, Molecular dynamics simulations of irradiation defects in graphite: Single crystal mechanical and thermal properties, Computational Materials Science 113 (2016) 60 - 65, ISSN 0927-0256, doi: http://doi.org/10.1016/j.commatsci.2015.11.012.

[14] R. Krishna, A. Jones, L. McDermott, B. Marsden, Neutron irradiation damage of nuclear graphite studied by high-resolution transmission electron microscopy and Raman spectroscopy, J. Nucl. 

publisher's policies. Please refer to any applicable terms of use of the publisher.

Mater. 467, Part 2 (2015) 557 - 565, ISSN 0022-3115, doi: http://dx.doi.org/10.1016/j.jnucmat.2015.10.027.

[15] Z. Zhou, W. Bouwman, H. Schut, T. van Staveren, M. Heijna, C. Pappas, Influence of neutron irradiation on the microstructure of nuclear graphite: An X-ray diffraction study, J. Nucl. Mater. 487 (2017) 323 - 330, ISSN 0022-3115, doi:http://dx.doi.org/10.1016/j.jnucmat.2017.02.004.

[16] J. Best, W. Stephen, A. Wickham, Radiolytic graphite oxidation, Prog Nucl Energ 16 (2) (1985) 127 - 178, ISSN 0149-1970, doi: http://dx.doi.org/10.1016/0149-1970(85)90002-2.

[17] Z. Mileeva, D. Ross, S. King, A study of the porosity of nuclear graphite using small-angle neutron scattering, Carbon 64 (2013) 20 - 26, ISSN 00086223, doi:http://doi.org/10.1016/j.carbon.2013.06.030.

[18] E. D. Eason, G. N. Hall, B. J. Marsden, G. B. Heys, Models of bending strength for Gilsocarbon graphites irradiated in inert and oxidising environments, J. Nucl. Mater. 436 (1 - 3) (2013) 208 - 216, ISSN 0022-3115, doi:http://doi.org/10.1016/j.jnucmat.2012.06.034.

[19] Y. Vertyagina, T. J. Marrow, Multifractal-based assessment of Gilsocarbon graphite microstructures, Carbon 109 (2016) 711 - 718, ISSN 0008-6223, doi:http://doi.org/10.1016/j.carbon.2016.08.049.

[20] M. Srinivasan, S. Mohanty, S. Majumdar, HTGR Graphite Core Component Stress Analysis Research - Program Task 1 Technical Letter Report., NRC, NUREG Report Washintgon, DC (2011) 1-139, ISSN ANL-11/04.

[21] W. Choi, B. Kim, E.-S. Kim, S. Chi, S. Park, Oxidation behavior of IG and NBG nuclear graphites, Nucl. Eng. Des 241 (1) (2011) 82 - 87, ISSN 0029-5493, doi:http://dx.doi.org/10.1016/j.nucengdes.2010.10.007.

[22] W.-H. Huang, S.-C. Tsai, I.-C. Chiu, C.-H. Chen, J.-J. Kai, The oxidation effects of nuclear graphite during air-ingress accidents in HTGR, Nucl. Eng. Des. 271 (2014) 270-274, ISSN 0029-5493, doi: http://dx.doi.org/10.1016/j.nucengdes.2013.11.047. 

publisher's policies. Please refer to any applicable terms of use of the publisher.

[23] C. Berre, S. Fok, B. Marsden, L. Babout, A. Hodgkins, T. Marrow, P. Mummery, Numerical modelling of the effects of porosity changes on the mechanical properties of nuclear graphite, J. Nucl. Mater. 352 (1 - 3) (2006) $1-5$.

[24] T. Shibata, J. Sumita, T. Tada, S. Hanawa, K. Sawa, T. Iyoku, Nondestructive evaluation methods for degradation of IG-110 and IG-430 graphite, J. Nucl. Mater. 381 (1 - 2) (2008) 165 - 170, ISSN 0022-3115, doi: http://doi.org/10.1016/j.jnucmat.2008.07.014, proceedings of the Seventh and Eighth International Graphite Specialists Meetings (INGSM).

[25] B. H. Park, H. C. NO, A unified model for strength degradation of oxidized IG-430 graphite column in VHTR, J. Nucl. Mater. 424 (1 - 3) (2012) 132 - 137, ISSN 0022-3115, doi:http://doi.org/10.1016/j.jnucmat.2012.02.009.

[26] J. B. Spicer, L. R. Olasov, F. W. Zeng, K. Han, N. C. Gallego, C. I. Contescu, Laser ultrasonic assessment of the effects of porosity and microcracking on the elastic moduli of nuclear graphites, J. Nucl. Mater. 471 (2016) 80 - 91, ISSN 0022-3115, doi:http://doi.org/10.1016/j.jnucmat.2015.12.015.

[27] M. S. El-Genk, J. P. Tournier, Comparison of oxidation model predictions with gasification data of IG-110, IG-430 and NBG-25 nuclear graphite, J. Nucl. Mater. 420 (1-3) (2012) 141-158, ISSN 0022-3115, doi: http://dx.doi.org/10.1016/j.jnucmat.2011.09.027.

[28] P. Wang, C. I. Contescu, S. Yu, T. D. Burchell, Pore structure development in oxidized IG-110 nuclear graphite, J. Nucl. Mater. 430 (1-3) (2012) 229238 .

[29] Z. He, L. Gao, W. Qi, B. Zhang, X. Wang, J. Song, X. He, C. Zhang, H. Tang, R. Holmes, H. Xia, X. Zhou, Molten FLiNaK salt infiltration into degassed nuclear graphite under inert gas pressure, Carbon 84 (2015) 511 - 518, ISSN 0008-6223, doi:http://doi.org/10.1016/j.carbon.2014.12.044.

[30] S.-P. Jing, C. Zhang, J. Pu, H. Jiang, H. Xia, F. Wang, X. Wang, J. Wang, C. Jin, 3D microstructures of nuclear graphite: IG-110, NBG-18 and NGCT-10, Nucl. Sci. Tech. 27 (3) (2016) 66. 

publisher's policies. Please refer to any applicable terms of use of the publisher.

[31] D. Chen, Z. Li, W. Miao, Z. Zhang, Effects of Porosity and Temperature on Oxidation Behavior in Air of Selected Nuclear Graphites, Mater. T. Jim 53 (6) (2012) 1159-1163, doi:10.2320/matertrans.MBW201107.

[32] C. Silva, L. Snead, J. Hunn, E. Specht, K. Terrani, Y. Katoh, Application of X-ray microcomputed tomography in the characterization of irradiated nuclear fuel and material specimens, J Microsc-Oxford 260 (2) (2015) 163174, doi:10.1111/mi.12279.

[33] C. I. Contescu, T. D. Burchell, Characterizarion of Porosity Development in Oxidized Graphite using Automated Image Analysis Techniques, Oak Ridge National Laboratory Report - for U.S Department of Energy (ORNL/TM-2009/192) (2009) 1-23, doi:10.2172/970899.

[34] J. Sumita, T. Shibata, I. Fujita, E. Kunimoto, M. Yamaji, M. Eto, T. Konishi, K. Sawa, Development of evaluation method with X-ray tomography for material property of IG-430 graphite for VHTR/HTGR, Nuclear Engineering and Design 271 (2014) 314 - 317, ISSN 0029-5493, doi:http://doi.org/10.1016/j.nucengdes.2013.11.053.

[35] C. I. Contescu, T. Guldan, P. Wang, T. D. Burchell, The effect of microstructure on air oxidation resistance of nuclear graphite, Carbon 50 (9) (2012) 3354-3366, ISSN 0008-6223, doi: http://dx.doi.org/10.1016/j.carbon.2012.01.040.

[36] K.-Y. Cho, K.-J. Kim, Y.-S. Lim, S.-H. Chi, Oxidation Behaviour of Nuclear Graphite (IG110) with Surface Roughness, J. Korean. Ceram. Soc. 43 (10) (2006) 613-618, doi:10.4191/KCERS.2006.43.10.613.

[37] J. Song, Y. Zhao, J. Zhang, X. He, B. Zhang, P. Lian, Z. Liu, D. Zhang, Z. He, L. Gao, H. Xia, X. Zhou, P. Huai, Q. Guo, L. Liu, Preparation of binderless nanopore-isotropic graphite for inhibiting the liquid fluoride salt and Xe135 penetration for molten salt nuclear reactor, Carbon 79 (2014) 36 - 45, ISSN 0008-6223, doi:http://dx.doi.org/10.1016/j.carbon.2014.07.022.

[38] Z. Li, D. Chen, X. Fu, W. Miao, Z. Zhang, The Influence of Pores on Irradiation Property of Selected Nuclear Graphites, Adv. Mater. Sci. Eng. 2012 (Article ID 640462) (2012) 6, doi:doi:10.1155/2012/640462. 
This is the author's accepted manuscript. The final published version of this work (the version of record) is published by Elsevier in Carbon (March 2018) available at: http://doi.org/10.1016/j.carbon.2017.11.076. This work is made available online in accordance with the publisher's policies. Please refer to any applicable terms of use of the publisher.

[39] H. Zhen, L. Zhengca, C. Dongyue, M. Wei, Z. Zhengjun, CO2 corrosion of IG-110 nuclear graphite studied by gas chromatography, J. Nucl. Sci. Technol. 51 (4) (2014) 487-492, ISSN 0022-3131, doi: 10.1080/00223131.2013.877407.

[40] W.-H. Huang, S.-C. Tsai, C.-W. Yang, J.-J. Kai, The relationship between microstructure and oxidation effects of selected IG- and NBG-grade nuclear graphites, J. Nucl. Mater. 454 (1-3) (2014) 149-158, ISSN 0022-3115, doi: http://dx.doi.org/10.1016/j.jnucmat.2014.07.052.

[41] S. Rigby, M. Watt-Smith, R. Fletcher, Simultaneous determination of the pore-length distribution and pore connectivity for porous catalyst supports using integrated nitrogen sorption and mercury porosimetry, Journal of Catalysis 227 (1) (2004) 68-76, doi:10.1016/j.jcat.2004.06.025.

[42] J. Kenvin, J. Jagiello, S. Mitchell, J. Pérez-Ramírez, Unified Method for the Total Pore Volume and Pore Size Distribution of Hierarchical Zeolites from Argon Adsorption and Mercury Intrusion, Langmuir 31 (4) (2015) 1242-1247, doi:10.1021/la504575s, pMID: 25603366.

[43] B. Bafarawa, A. Nepryahin, L. Ji, E. M. Holt, J. Wang, S. P. Rigby, Combining mercury thermoporometry with integrated gas sorption and mercury porosimetry to improve accuracy of pore-size distributions for disordered solids, Journal of Colloid and Interface Science 426 (2014) 72 79, ISSN 0021-9797, doi:http://dx.doi.org/10.1016/j.jcis.2014.03.053.

[44] P. E. Dim, R. S. Fletcher, S. P. Rigby, Improving the accuracy of catalyst pore size distributions from mercury porosimetry using mercury thermoporometry, Chemical Engineering Science 140 (2016) 291 - 298, ISSN 0009-2509, doi:http://dx.doi.org/10.1016/j.ces.2015.10.023.

[45] T. J. Mays, A new classification of pore sizes, in: F. R.-R. J. R. P.L. Llewellyn, N. Seaton (Eds.), Studies in Surface Science and Catalysis, vol. 160, Elsevier, 57-62, 2007.

[46] M. T. Miyahara, R. Numaguchi, T. Hiratsuka, K. Nakai, H. Tanaka, Fluids in nanospaces: molecular simulation studies to find out key mechanisms 

publisher's policies. Please refer to any applicable terms of use of the publisher.

for engineering, Adsorption 20 (2) (2014) 213-223, ISSN 1572-8757, doi: $10.1007 / \mathrm{s} 10450-013-9588-2$.

[47] J. M. Dickinson, J. W. Shore, Observations concerning the determination of porosities in graphites, Carbon 6 (1968) 937-941.

[48] D. J. Baker, J. B. Morris, Structural damage in graphite occuring during pore size measurements by hugh pressure mercury, Carbon 9 (1971) 687690.

[49] G. Matthews, C. Canonville, A. Moss, Use of a void network model to correlate porosity, mercury porosimetry, thin section, absolute permeability, and NMR relaxation time data for sandstone rocks, Physical Review E $73(3,1)$, ISSN 1539-3755, doi:10.1103/PhysRevA.73.031307.

[50] G. M. Laudone, C. M. Gribble, G. P. Matthews, Characterisation of the porous structure of Gilsocarbon graphite using pycnometry, cyclic porosimetry and void-network modeling, Carbon 73 (2014) 61-70, ISSN 0008-6223, doi:http://dx.doi.org/10.1016/j.carbon.2014.02.037.

[51] X. Yan, X. YAN, Y. Tachibana, H. Ohashi, H. Sato, Y. Tazawa, K. Kunnitomi, A small modular reactor design for multiple energy applications: HTR50S, Nucl. Eng. Techno 45 (3) (2013) 401 - 414, ISSN 1738-5733, doi:http://dx.doi.org/10.5516/NET.10.2012.070.

[52] H. Zhen, L. Zhengcao, C. Dongyue, M. Wei, Z. Zhengjun, CO2 corrosion of IG-110 nuclear graphite studied by gas chromatography, J Nucl. Sci. Technol. 51 (4) (2014) 487-492, doi: http://dx.doi.org/10.1080/00223131.2013.877407.

[53] S. Brunauer, P. Emmett, E. Teller, Adsorption of gases in multimolecular layers, Journal of the American Chemical Society 60 (1938) 309-319.

[54] E. P. Barrett, L. G. Joyner, P. P. Halenda, The Determination of Pore Volume and Area Distributions in Porous Substances. I. Computations from Nitrogen Isotherms, Journal of the American Chemical Society 73 (1) (1951) $373-380$. 
This is the author's accepted manuscript. The final published version of this work (the version of record) is published by Elsevier in Carbon (March 2018) available at: http://doi.org/10.1016/j.carbon.2017.11.076. This work is made available online in accordance with the publisher's policies. Please refer to any applicable terms of use of the publisher.

[55] J. van Brakel, S. Modry, M. Svata, Mercury Porosimetry: State of the Art, Powder Technology 29 (1981) 1-12.

[56] P. A. Bodurtha, G. P. Matthews, J. P. Kettle, I. M. Roy, Influence of anisotropy on the dynamic wetting and permeation of paper coatings, Journal of Colloid and Interface Science 283 (1) (2005) 171 - 189, ISSN 0021-9797, doi:http://dx.doi.org/10.1016/j.jcis.2004.08.072.

[57] G. P. Matthews, G. M. Laudone, A. S. Gregory, N. R. A. Bird, A. G. de G. Matthews, W. R. Whalley, Measurement and simulation of the effect of compaction on the pore structure and saturated hydraulic conductivity of grassland and arable soil, Water Resources Research 46 (5) (2010) n/an/a, ISSN 1944-7973, doi:10.1029/2009WR007720, w05501.

[58] G. M. Laudone, G. P. Matthews, A. S. Gregory, N. R. A. Bird, W. R. Whalley, A dual-porous, inverse model of water retention to study biological and hydrological interactions in soil, European Journal of Soil Science 64 (3) (2013) 345-356, ISSN 1365-2389, doi:10.1111/ejss.12055.

[59] J. C. Price, G. P. Matthews, K. Quinlan, J. Sexton, A. G. de G. Matthews, A depth filtration model of straining within the void networks of stainless steel filters, AIChE Journal 55 (12) (2009) 3134-3144, ISSN 1547-5905, doi:10.1002/aic.11925.

[60] G. P. Matthews, Computer modelling of fluid interactions in porous coatings and paper - an overview, Nord Pulp Pap Res J 15 (5) (2000) $341-372$.

[61] G. Laudone, C. Gribble, K. Jones, H. Collier, G. Matthews, Validated a priori calculation of tortuosity in porous materials including sandstone and limestone, Chemical Engineering Science 131 (2015) 109-117, doi: 10.1016/j.ces.2015.03.043, cited By 1.

[62] J. C. Groen, L. A. Peffer, J. Pérez-Ramírez, Pore size determination in modified micro- and mesoporous materials. Pitfalls and limitations in gas adsorption data analysis, Microporous and Mesoporous Materials 60 (1) (2003) 1 - 17, ISSN 1387-1811, doi:http://dx.doi.org/10.1016/S13871811(03)00339-1. 

publisher's policies. Please refer to any applicable terms of use of the publisher.

[63] M. Thommes, K. Kaneko, A. V. Neimark, J. Olivier, F. Rodriguez-Reinoso,

J. Rouquerol, K. Sing, Physisorption of gases, with special reference to the evaluation of surface area and pore size distribution (IUPAC Technical Report), in: Pure and Applied Chemistry, vol. 87, 2015.

[64] M. Ban̄ares-Mun̄oz, L. González, J. Llorenta, Adsorption isotherms of nitrogen and argon on an agot grade artificial nuclear graphite at 77 and 90 K, doi:https://doi.org/10.1016/0008-6223(87)90210-7, 1987.

[65] C. M. Öberg, B. Rippe, A distributed two-pore model: theoretical implications and practical application to the glomerular sieving of Ficoll, American Journal of Physiology - Renal Physiology 306 (8) (2014) F844F854, ISSN 1931-857X, doi:10.1152/ajprenal.00366.2013.

[66] G. P. Matthews, C. F. Canonville, A. K. Moss, Use of a void network model to correlate porosity, mercury porosimetry, thin section, absolute permeability, and NMR relaxation time data for sandstone rocks, Phys. Rev. E 73 (2006) 031307, doi:10.1103/PhysRevE.73.031307.

[67] D. Liu, B. Gludovatz, H. S. Barnard, M. Kuball, R. O. Ritchie, Damage tolerance of nuclear graphite at elevated temperatures, Nat. Commun. 8 (15942), doi:http://dx.doi.org/10.1038/ncomms15942. 